 \\ Clinical Research andTherapeutics \\ Mary Ann Lielest, Inc. Fublishers
}

\section{Clomiphene Citrate for Male Hypogonadism and Infertility: An Updated Review}

\author{
Bryan J. Herzog, Hoang Minh Tue Nguyen, Ayman Soubra, and Wayne J.G. Hellstrom*
}

\begin{abstract}
Clomiphene citrate (CC) is a selective estrogen receptor modulator, originally developed in 1956 and introduced into clinical medicine in 1967 for the treatment of female infertility. CC has also been explored for off-label use for male infertility and male hypogonadal symptoms. This article will review the medical literature on CC and its contribution to the treatment of male hypogonadism. A comprehensive review of the literature pertaining to CC through April 2020 was performed through PubMed. We included 52 articles that were relevant to CC. Abstracts and case reports were not included in this comprehensive review. CC as a monotherapy, as well as CC combined with vitamins and other non-Food and Drug Administration-approved substances, has been shown to have mixed results in improving male factor infertility. A variety of questionnaires have been used to describe changes in hypogonadal symptoms with CC treatment. Articles have reported conflicting outcomes regarding improved hypogonadal symptoms with CC treatment. CC is generally considered a safe drug, and the majority of CC studies do not report any significant side effects. Side effects that have been reported include headache, gynecomastia, visual disturbances, dizziness, and mood instability. CC is regarded as an effective therapy for specific patients who suffer from male factor infertility and complain of hypogonadal symptoms. More studies are needed to further validate CC's efficacy for male infertility and hypogonadism.
\end{abstract}

Keywords: clomiphene citrate; hypogonadism; testosterone; drug treatment; clomid

\section{Introduction}

The prevalence of male hypogonadism is estimated to be between $2 \%$ and $13 \%$ of the adult male population in the world. ${ }^{1}$ Incidence rises with age, with up to $40 \%$ of men aged $\geq 45$ years diagnosed with hypogonadism through various testosterone assays. ${ }^{2}$ In middle-aged men, total testosterone is approximated to have a $0.8-1.6 \%$ yearly decline. ${ }^{3}$ Decreased libido, depressed mood, lack of energy, diminished mental concentration, erectile dysfunction, and decreased muscle mass are common presenting complaints of hypogonadal men. ${ }^{4}$

The most common treatment for hypogonadism in men is testosterone replacement therapy (TRT), which has seen a significant increase in recent years. A 2013 study by the Food and Drug Administration (FDA) observed that the number of TRT prescriptions had increased from 1.2 to 2.2 million patients over 2009-2012 (12.4\% of these patients were $\leq 39$ years). ${ }^{5}$ Side effects of exogenous TRT are significant and include male infertility, testicular atrophy, gynecomastia, secondary polycythemia, and acne. ${ }^{6}$ TRT impairs fertility by suppressing spermatogenesis, as well as endogenous testosterone production. The mechanism of this is suppression of the hypothalamic-pituitary-gonadal (HPG) axis, thereby decreasing production of luteinizing hormone (LH) and follicle-stimulating hormone (FSH). ${ }^{6}$ The American

Department of Urology, Tulane University School of Medicine, New Orleans, Louisiana, USA.

*Address correspondence to: Wayne J.G. Hellstrom, MD, FACS, Department of Urology, Tulane University School of Medicine, 1430 Tulane Avenue, 8642 , New Orleans, LA 70112, USA, E-mail: whellst@tulane.edu

(C) Bryan J. Herzog et al., 2020; Published by Mary Ann Liebert, Inc. This Open Access article is distributed under the terms of the Creative Commons License (http://creativecommons.org/licenses/by/4.0), which permits unrestricted use, distribution, and reproduction in any medium, provided the original work is properly cited. 
Urological Association (AUA) 2018 guidelines recommend that men with testosterone deficiency, but who are still interested in fertility, undergo a reproductive evaluation in which they are also made aware of the long-term impact of exogenous testosterone on spermatogenesis and fertility. ${ }^{7}$ Clomiphene citrate (CC) is an off-label treatment for hypogonadism and is among the drugs conditionally supported by AUA guidelines in the treatment of hypogonadal men who desire to preserve fertility. ${ }^{7}$

This communication reviews the published medical literature on CC and its contribution to the treatment of male hypogonadism.

\section{Materials and Methods}

We performed a comprehensive literature search using PubMed through April 2020, using keywords such as clomid, CC, hypogonadism, infertility, symptoms, and testosterone. The list of publications was reviewed independently by two authors (B.J.H. and H.M.T.N.) and conflicts regarding inclusion were resolved by examining the full text and discussion among the authors. For the purpose of this review, only full-text publications were included. Case reports and abstracts were excluded from this review. Articles in languages other than English were also excluded. Figure 1 shows the pathway for our literature search and selection of the included studies.

\section{Background}

CC is a selective estrogen receptor modulator that was originally developed by Frank Palopoli and his colleagues at the William S. Merrell Company in 1956 as a potential contraceptive. It was then discovered to aid in fertility in women and first introduced into clinical medicine around 1967. The FDA initially approved this drug to promote ovulation in patients with anovulatory conditions, such as polycystic ovarian syndrome, but the drug was also observed to increase the sensitivity of ovarian cells to pituitary hormones. ${ }^{8}$ The innovations in the treatment of female infertility provided a better understanding of CC's effect on the HPG axis, and the drug was later explored for off-label use for male factor infertility. ${ }^{9}$ Since its introduction to the area of male infertility, CC has also contributed to the treatment of symptoms associated with hypogonadism.

\section{Mechanism of Action}

The HPG axis in males includes the hypothalamus, the anterior pituitary gland, and the testicles. Gonadotropinreleasing hormone $(\mathrm{GnRH})$ is produced from the hypothalamus, which stimulates the production of $\mathrm{LH}$ and FSH in the anterior pituitary gland. LH and FSH released from the anterior pituitary promote the production of testosterone and spermatogenesis. Testosterone is then converted to estradiol by the aromatase enzyme.

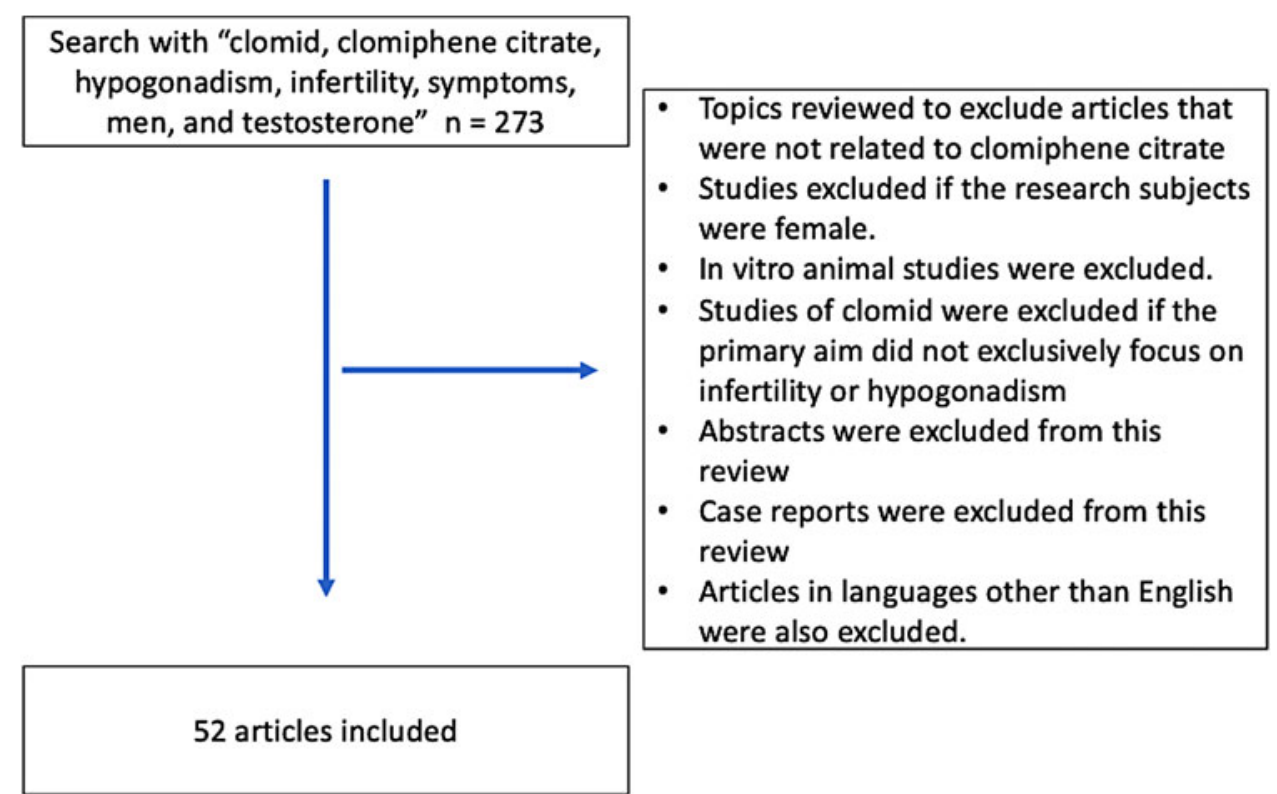

FIG. 1. Literature review methodology. 
Estradiol in the normal physiological state exhibits part of the negative feedback mechanism on the reproductive axis by binding to the hypothalamus, which inhibits the continuous release of GnRH. CC competes with estradiol at the hypothalamic receptor level, specifically located on the anterior hypothalamus and hypophysis, which blocks the negative feedback mechanism and results in increased GnRH. CC has a half-life of 5 days and is an isomer that consists of two compounds, $38 \%$ zuclomiphene (cis-isomer) and 62\% enclomiphene, which are both excreted through the intestines. ${ }^{8}$ Zuclomiphene is both a partial estrogen agonist and estrogen antagonist, whereas enclomiphene is completely antiestrogenic. Unlike testosterone, both compounds do not suppress the HPG axis, but actually lead to an increase in $\mathrm{LH}$ and $\mathrm{FSH}$, which results in an increased production of intratesticular testosterone by the Leydig cells and the promotion of spermatogenesis. ${ }^{9,10}$

Enclomiphene alone, which is a pure estrogen antagonism unlike the combination in CC, has also been investigated as a therapeutic alternative to treat hypogonadism. Wiehle et al. ${ }^{11}$ evaluated its effectiveness on spermatogenesis and documented that all of the hypogonadal patients treated with enclomiphene $25 \mathrm{mg}$ daily remained normospermic by the end of treatment. In a randomized controlled trial, Kim et al. ${ }^{12}$ documented no significant differences in sperm parameters between enclomiphene and placebo in hypogonadal men over a 5-month treatment period.

CC is also recognized to affect the testosterone-toestrogen (T:E) ratio. An increase in this ratio is postulated to improve fertility potential by preventing the negative effects of estrogen on the hypothalamus. Increased estrogen and aromatase activity in the testicles theoretically decreases sperm counts and increases the likelihood of embryo loss before and after egg implantation into the uterus. ${ }^{13,14}$ Anastrozole (AZ) is also an effective treatment in lowering estrogen levels for patients by blocking the conversion of T:E facilitated by the aromatase enzyme, which leads to an increased T:E ratio. Sperm concentration and motility have been documented to improve in hypogonadal men who had optimized T:E ratios after 5 months of AZ treatment. ${ }^{15,16}$ A prospective study revealed an increase in the T:E ratios by $60.9 \%$ at 12 weeks of $25 \mathrm{mg}$ daily of CC treatment, with a more significant rise in $\mathrm{T}$ : $\mathrm{E}$ in $\geq 40$-year-old men when compared with those $<40$ years old. ${ }^{17}$ A retrospective cohort study determined that patients who had a baseline estradiol of $\geq 18.5 \mathrm{pg} / \mathrm{mL}$ and a body mass index (BMI) $\geq 29$ should have $\mathrm{AZ}$ combined with CC $50 \mathrm{mg}$ every other day to maintain a T:E $>10$ and estradiol levels $<50 \mathrm{pg} / \mathrm{mL}^{18}$

\section{Use for Infertility}

It has been reported in a number of studies that CC restores fertility in hypogonadal patients by exhibiting increases in sperm concentration. Table 1 summarizes the significant studies for the treatment of male infertility with CC. There has been several randomized controlled trials to address this question. Ronnberg. ${ }^{19}$ observed, in a randomized double crossover study, an increase in sperm count when patients were prescribed $50 \mathrm{mg}$ CC daily. In a World Health Organization trial including 190 infertile couple treated with daily dose of $25 \mathrm{mg}$ CC, the study observed a statistically significant increase in sperm concentration at 4 months in the CC group, but reported no significant increase in pregnancy rate and no other changes in sperm parameters with CC treatment. ${ }^{20}$ Wang et al. ${ }^{21}$ and Micic and Dotlic $^{22}$ also demonstrated an increase in sperm concentration when receiving CC therapy. A retrospective cohort study evaluating sperm concentrations in hypogonadal infertile men with type 2 diabetes mellitus documented a significant increase in sperm concentration after 3 months of treatment with CC $50 \mathrm{mg}$ every other day plus metformin compared with placebo plus metformin. ${ }^{23}$ Hussein et al. ${ }^{24}$ demonstrated that infertile men who are severely oligospermic have a higher likelihood of successful microscopic testicular sperm extraction after 9 months of CC treatment when compared with placebo.

There have also been a number of studies that reported CC having no significant effect on sperm parameters. Sokol et al. ${ }^{25}$ randomly assigned 23 hypogonadal men to either CC $25 \mathrm{mg}$ daily or placebo, and no significant changes in sperm parameters were observed between the two treatment groups in a 12 -month period. A double-blinded randomized controlled trial did not demonstrate a significant increase of sperm parameters in hypogonadal infertile men prescribed CC, although the majority of men included in this study were not oligospermic at baseline, and more than half of the individuals had varicoceles. ${ }^{26}$ Another retrospective cross-sectional did not demonstrate a significant increase in sperm parameters in 47 hypogonadal men after 3 months of treatment with CC $50 \mathrm{mg}$ every other day. ${ }^{27}$ In one randomized controlled trial, there were no significant changes in serum anti-Müllerian hormone and inhibin levels in hypogonadal men with metabolic syndrome who were treated with CC $25 \mathrm{mg}$ 
Table 1. Summary of Studies for Treatment of Infertility with Clomiphene Citrate

\begin{tabular}{|c|c|c|c|c|c|c|}
\hline Study & Year & Study design & $\begin{array}{l}\text { Number } \\
\text { of subjects }\end{array}$ & Treatment regimen & $\begin{array}{l}\text { Study } \\
\text { duration }\end{array}$ & Primary outcome in CC group \\
\hline Ronnberg $^{19}$ & 1980 & $\begin{array}{l}\text { Double-blind } \\
\text { crossover study }\end{array}$ & 30 & $\begin{array}{l}\text { CC } 50 \mathrm{mg} \text { daily } 3 \text { months } \times 2 \\
\text { with } 3 \text { months washout in } \\
\text { between }\end{array}$ & 9 Months & Higher sperm count in CC group \\
\hline Micic and Dotlic ${ }^{22}$ & 1985 & $\mathrm{RCT}$ & 101 & CC 50 mg daily & 6-9 Months & $\begin{array}{l}\text { Improvement in sperm volume, } \\
\text { density, and motility }\end{array}$ \\
\hline Sokol et al. ${ }^{25}$ & 1988 & $\mathrm{RCT}$ & 23 & CC 25 mg daily & 3 Months & $\begin{array}{l}\text { No difference in sperm volume, } \\
\text { density, and motility }\end{array}$ \\
\hline $\begin{array}{l}\text { World Health } \\
\text { Organization }^{20}\end{array}$ & 1992 & $\mathrm{RCT}$ & 190 & CC 25 mg daily & 3 Months & $\begin{array}{l}\text { No difference in pregnancy rate. No } \\
\text { change in sperm parameters }\end{array}$ \\
\hline Wang et al. ${ }^{21}$ & 1993 & $\mathrm{RCT}$ & 46 & CC $25 \mathrm{mg}$ or CC $50 \mathrm{mg}$ daily & 6 Months & Increased sperm count in CC group \\
\hline Hussein et al. ${ }^{24}$ & 2012 & Prospective cohort & 488 & $\begin{array}{l}\text { Titrated CC dose until T is } \\
600-800 \mathrm{ng} / \mathrm{dL}\end{array}$ & 3 Months & $\begin{array}{l}\text { Higher probability of successful } \\
\text { sperm extraction with micro-TESE }\end{array}$ \\
\hline ElSheikh et al. ${ }^{30}$ & 2015 & $\mathrm{RCT}$ & 90 & $\begin{array}{l}\text { CC } 25 \mathrm{mg} \text { daily or vitamin } \mathrm{E} \\
400 \mathrm{mg} \text { daily }\end{array}$ & 3-6 Months & $\begin{array}{l}\text { Significant increase in sperm } \\
\text { concentration in CC group over } \\
\text { 3-month intervals }\end{array}$ \\
\hline Helo et al. $^{26}$ & 2015 & $\mathrm{RCT}$ & 26 & CC 25 mg daily & 12 Weeks & No difference in sperm concentration \\
\hline Surbone et al. ${ }^{23}$ & 2020 & Retrospective cohort & 18 & CC $50 \mathrm{mg}$ every other day & 3 Months & Improvement in sperm concentration \\
\hline
\end{tabular}

daily for 3 months; however, the majority of the men in this study had at least one child in the past, and normal sperm parameters. ${ }^{28}$

Vitamins and other non-FDA-approved nutritional supplements have also been studied in regard to pregnancy rates and sperm parameters when combined with CC treatment. Reactive oxidative agents have been determined to alter sperm production and sperm quality, and the use of vitamins may have beneficial effects on patients who suffer with infertility. ${ }^{29}$ ElSheikh et al. ${ }^{30}$ performed a prospective cohort study evaluating effects of $\mathrm{CC}$ and vitamin $\mathrm{E}$ on sperm parameters on hypogonadal oligoathenospermic men. The study observed a significant increase in sperm concentration in patients receiving $\mathrm{CC}$, and an even greater increase in sperm concentration when individuals were taking both $\mathrm{CC}$ and vitamin E. ${ }^{30}$ A double-blinded randomized controlled trial of 60 infertile men with an average duration of infertility of 4.5 years demonstrated an increase in pregnancies with the treatment group, which received CC $25 \mathrm{mg}$ daily plus vitamin E $400 \mathrm{mg}$ daily, at a 3- to 6-month follow-up period versus the placebo group (36.7\% vs. $13.3 \%){ }^{31}$ In another randomized controlled trial, sperm parameters were evaluated between individuals on a treatment regimen of CC $50 \mathrm{mg}$ daily or $200 \mathrm{mg}$ vitamin $\mathrm{C}$ and found no significant difference between the treatment group's rates of pregnancies overall. This study did report an increase in pregnancy rates with individuals taking CC who had a duration of infertility of $<18$ months before initiating treatment. ${ }^{32}$ An additional randomized control trial saw investigators document that men who received
CC or L-carnitine experienced an increase in sperm motility compared with the placebo group. ${ }^{33}$

\section{Use for Men with Hypogonadism}

Studies have shown that the use of CC significantly improves hypogonadal symptoms assessed by answer to various questionnaires. Table 2 summarizes the significant studies for the treatment of hypogonadal symptoms with CC. Guay et al. $^{34}$ used rigidity tests and the international index of erectile function/sexual health inventory for men (SHIM) to assess response to CC therapy. This study did not demonstrate significant changes in sexual function nor rigidity in the entire cohort, but a subset analysis noted that younger men (mean age 53 years), as well as men without diabetes and hypertension, had improved rigidity and sexual function with CC treatment versus placebo. ${ }^{34}$ The same researcher also demonstrated in one other study that men $\leq 55$ years and younger were 2.3 times more likely to have a positive response to CC treatment compared with men who were $>55$ years. A positive response was defined as completing intercourse in $>50 \%$ of attempts. ${ }^{35}$ In another study, investigators did not observe improvement in SHIM scores after 1 year of treatment with CC. Other outcomes that were observed in hypogonadism included increased BMI and a decline in bone density. ${ }^{36}$ Also, the use of CC has demonstrated improved bone density and decreased BMI in hypogonadal individuals over a 3 -year treatment period. ${ }^{37}$

The androgen deficiency in aging males (ADAM) questionnaire was utilized in a majority of studies to evaluate CC and its effect on hypogonadal symptoms. 
Table 2. Summary of Studies for Treatment of Hypogonadal Symptoms with Clomiphene Citrate

\begin{tabular}{|c|c|c|c|c|c|c|}
\hline Study & Year & Study design & $\begin{array}{l}\text { Number } \\
\text { of subjects }\end{array}$ & Treatment regimen & $\begin{array}{l}\text { Study } \\
\text { duration }\end{array}$ & Primary outcome in CC group \\
\hline Guay et al. ${ }^{34}$ & 1995 & Double-blind crossover & 17 & $\begin{array}{l}\text { CC } 50 \text { mg every other day } \times 2 \\
\text { months with } 2 \text { weeks } \\
\text { washout in between }\end{array}$ & 5 Months & $\begin{array}{l}\text { No difference in sexual function } \\
\text { or nocturnal tumescence and } \\
\text { rigidity }\end{array}$ \\
\hline Guay et al. ${ }^{35}$ & 2003 & Retrospective cohort & 228 & CC $50 \mathrm{mg}$ every other day & 4 Months & $\begin{array}{l}\text { Men }<55 \text { years old more likely to } \\
\text { successfully complete sexual } \\
\text { intercourse }\end{array}$ \\
\hline Taylor and Levine ${ }^{41}$ & 2010 & Retrospective cohort & 22 & $\begin{array}{l}\text { Titrated CC dose until T is } \\
550 \mathrm{ng} / \mathrm{dL}\end{array}$ & 23-46 Months & Improvement in ADAM score \\
\hline Moskovic et al. ${ }^{37}$ & 2012 & Retrospective cohort & 46 & CC $25 \mathrm{mg}$ every other day & 12-36 Months & Improvement in ADAM score \\
\hline Katz et al. ${ }^{42}$ & 2012 & Retrospective cohort & 86 & $\begin{array}{l}\text { Titrated CC dose until } \\
\mathrm{T} \sim 550 \mathrm{ng} / \mathrm{dL}\end{array}$ & 6 Months & Improvement in ADAM score \\
\hline Ramasamy et al. ${ }^{47}$ & 2014 & Cross-sectional & 93 & CC $25 \mathrm{mg}$ daily or TRT & N/A & $\begin{array}{l}\text { Improvement qADAM score } \\
\text { seen in CC and TRT }\end{array}$ \\
\hline Helo et al. ${ }^{26}$ & 2015 & $\mathrm{RCT}$ & 26 & CC 25 mg daily & 12 Weeks & No difference in ADAM or IIEF \\
\hline Chandrapal et al. ${ }^{36}$ & 2016 & Retrospective cohort & 77 & CC $50 \mathrm{mg}$ every other day & 12 Months & $\begin{array}{l}\text { Improvement in ADAM score, } \\
\text { but not SHIM score }\end{array}$ \\
\hline Habous et al. ${ }^{46}$ & 2017 & $\mathrm{RCT}$ & 95 & $\begin{array}{l}\text { CC } 50 \text { mg daily or } 5000 \text { IU hCG } \\
\text { twice/week }\end{array}$ & 3 Months & Improvement in qADAM score \\
\hline Soares et al. ${ }^{43}$ & 2018 & $\mathrm{RCT}$ & 78 & CC $50 \mathrm{mg}$ daily & 12 Weeks & No improvement in ADAM score \\
\hline
\end{tabular}

ADAM, androgen deficiency in aging males; hCG, human chorionic gonadotropin; IIEF, International Index of Erectile Function; IU, international units; N/A, not applicable; qADAM, quantitative ADAM; SHIM, sexual health inventory for men; TRT, testosterone replacement therapy.

This questionnaire has a reported sensitivity and specificity of $97 \%$ and $30 \%$, respectively, with false positives when hypogonadal patients report depression. ${ }^{38-40}$ Taylor and Levine ${ }^{41}$ evaluated changes in hypogonadal symptoms in individuals treated with CC or testosterone gel by utilizing the ADAM score. Both groups achieved testosterone levels $\sim 550 \mathrm{ng} / \mathrm{dL}$ and reported improvement in libido by exhibiting a decrease in ADAM score. ${ }^{41}$ Katz et al. ${ }^{42}$ evaluated a cohort of 86 hypogonadal men prescribed $50 \mathrm{mg}$ CC every other day. This study demonstrated improvement in ADAM score after 6 months of treatment, and found no differences in symptom response to CC treatment in patients with varicoceles versus patients with no varicoceles. ${ }^{42}$ Patients have also demonstrated a significant improvement in ADAM scores after 1 year of receiving CC $50 \mathrm{mg}$ every day or every other day. ${ }^{36}$ One group of investigators performed a double-blind randomized controlled trial that evaluated changes in hypogonadal symptoms in obese hypogonadal men after 3 months of receiving CC versus placebo. This study did not record a significant difference between ADAM score improvement. ${ }^{43}$ Another randomized controlled trial evaluating changes in hypogonadal symptoms between CC and $\mathrm{AZ}$ treatment did not show significant improvement in ADAM scores after 3 months in either treatment group. ${ }^{26}$

The quantitative ADAM (qADAM) questionnaire was developed in 2010 to provide numerical values to the original ADAM questionnaire. A higher numerical score was associated with lower likelihood of hypogonadal symptoms when compared with total testosterone. No specific cutoff values were established to distinguish between positive and negative qADAM scores. The GADAM score also had a positive correlation with total testosterone and with SHIM scores. ${ }^{44}$ Dadhich et al. $^{45}$ evaluated changes in hypogonadal symptoms after 3 months of receiving CC or TRT, and observed a significant improvement in qADAM scores in both the CC and TRT group. Investigators, through a randomized controlled study, also reported that $\mathrm{CC}$ and human chorionic gonadotropin therapy both improved qADAM score when these treatment regimens were used separately or as a combination. ${ }^{46}$ Ramasamy et al. ${ }^{47}$ conducted a cross-sectional study that demonstrated an improvement in qADAM score with both CC $25 \mathrm{mg}$ daily and TRT, and did demonstrate a statistically significant difference between the two treatment regimens. Sertoli cell function has also been studied in hypogonadal men treated with CC by measuring serum inhibin and anti-Müllerian hormone. A retrospective cohort study revealed increased serum inhibin levels after treatment with CC $50 \mathrm{mg}$ every other day for 3 months. ${ }^{23}$

There is an issue on whether or not the ADAM questionnaire is proven to be a useful tool for monitoring hypogonadal symptoms in the setting of CC treatment, especially when the test was originally used to monitor 
hypogonadal systems, when specially using bioavailable testosterone. ${ }^{38}$ The majority of studies included in the literature that utilized the ADAM questionnaire were based on their definition of testosterone deficiency on total serum testosterone rather than bioavailable serum testosterone. Studies have demonstrated the inability to distinguish between individuals who had a positive or negative ADAM score when measuring total testosterone. ${ }^{39,48}$

In our practice, we obtain baseline laboratory values before starting the CC. Those include testosterone, estrogen, FSH, and LH. Then we start the lowest dose, which is $25 \mathrm{mg}$ every other day since patients respond differently. We recheck the laboratory values in 6-8 weeks and we titrate based on the response to these laboratory values, gradually going up to a maximum of $50 \mathrm{mg}$ daily depending on the response.

\section{Adverse Effects}

$\mathrm{CC}$ is generally regarded by investigators to be a tolerable drug in clinical practice. ${ }^{6}$ There have not been many studies investigating the adverse effects of CC in men, especially in comparison with TRT. Most studies reported no major side effects of CC while investigating its efficacy. ${ }^{17,21,47,49}$ Side effects reported with CC treatment include headache, gynecomastia, visual disturbances, dizziness, and mood instability. ${ }^{6,20,25,36}$ When compared with TRT in a multi-institutional retrospective study of 363 patients, Wheeler et al. noted that CC had lower prevalence of secondary polycythemia than TRT (1.7\% compared with $11.2 \%)$; no men in the CC arm had a hematocrit high enough to necessitate phlebotomy. ${ }^{50}$ In their study of 104 men, Taylor and Levine ${ }^{41}$ investigated the long-term safety and efficacy of CC versus testosterone gel and noted that CC did not significantly increase cholesterol, PSA, or hemoglobin. Chandrapal et al. $^{36}$ reported no effect of CC on PSA and hematocrit in their study of 77 patients on CC. One case reported switching TRT to CC in a patient with secondary polycythemia on TRT. This patient did not subsequently exhibit polycythemia on CC. ${ }^{51}$ Recently, Kavoussi et al. ${ }^{52}$ investigated the risk of deep vein thrombosis (DVT) in 1180 hypogonadal men either on TRT or CC and reported that only 1 out of 486 patients on CC developed DVT compared with 9 out of 694 patients on TRT. In a prospective study of 125 hypogonadal men on CC, Da Ros and Averbeck $^{49}$ did not find statistically significant differences when comparing pre- and post-treatment highdensity lipoprotein-cholesterol, triglycerides, fasting plasma glucose, and prolactin levels. These studies highlight the safety of CC, especially compared with TRT regarding secondary polycythemia and DVT risks.

\section{Conclusion}

$\mathrm{CC}$ is regarded as a useful treatment for men who suffer with both infertility and hypogonadal symptoms. CC is generally regarded as safe to prescribe to hypogonadal patients, which is highlighted in the majority of studies. There are mixed results in regard to CC treatment and its effect on sperm parameters throughout the literature. This could be due to the fact that CC is considered an off-label drug for the treatment of infertility and hypogonadism. Since CC is not FDA approved for male hypogonadism, there are no clear guidelines that dictate the correct dosage and frequency of CC treatment. There are also different inclusion and exclusion criteria that qualify subjects to be entered into each study. CC also has mixed results when its used for treating hypogonadal symptoms, which can be attributed to the poor diagnostic accuracy of the ADAM questionnaire. Overall, more studies that consist of criteria that are universally accepted by the male sexual health community would further validate CC's efficacy for infertility and hypogonadism.

\section{Authors' Contributions}

Conception and design were by W.J.G.H.; data acquisition and analysis were done by B.J.H. and H.M.T.N.; drafting of article by B.J.H., H.M.T.N., and A.S.; revising the article was by W.J.G.H.; approval by all authors.

\section{Author Disclosure Statement}

The authors report no competing or conflicts of interest.

\section{Funding Information}

No funding was granted in consideration for this article.

\section{References}

1. Zarotsky V, Huang MY, Carman W, et al. Systematic literature review of the risk factors, comorbidities, and consequences of hypogonadism in men. Andrology. 2014;2(6):819-834.

2. Mulligan T, Frick MF, Zuraw QC, Stemhagen A, McWhirter C. Prevalence of hypogonadism in males aged at least 45 years: The HIM study. Int J Clin Pract. 2006;60(7):762-769.

3. Mohr BA, Guay AT, O'Donnell AB, McKinlay JB. Normal, bound and nonbound testosterone levels in normally ageing men: Results from the Massachusetts Male Ageing Study. Clin Endocrinol (Oxf). 2005;62(1): 64-73.

4. Traish AM, Miner MM, Morgentaler A, Zitzmann M. Testosterone deficiency. Am J Med. 2011;124(7):578-587. 
5. Nguyen CP, Hirsch MS, Moeny D, Kaul S, Mohamoud M, Joffe HV. Testosterone and "age-related hypogonadism"-FDA concerns. N Engl J Med. 2015;373(8):689-691.

6. Wheeler KM, Sharma D, Kavoussi PK, Smith RP, Costabile R. Clomiphene citrate for the treatment of hypogonadism. Sex Med Rev. 2019;7(2): 272-276.

7. Mulhall JP, Trost LW, Brannigan RE, et al. Evaluation and management of testosterone deficiency: AUA guideline. J Urol. 2018;200(2): 423-432.

8. Dickey RP, Holtkamp DE. Development, pharmacology and clinical experience with clomiphene citrate. Hum Reprod Update. 1996;2(6) 483-506.

9. Mellinger RC, Thompson RJ. The effect of clomiphene citrate in male infertility. Fertil Steril. 1966;17(1):94-103.

10. Paulson DF, Wacksman J. Clomiphene citrate in the management of male infertility. J Urol. 1976;115(1):73-76.

11. Wiehle RD, Fontenot GK, Wike J, Hsu K, Nydell J, Lipshultz L. Enclomiphene citrate stimulates testosterone production while preventing oligospermia: A randomized phase II clinical trial comparing topical testosterone. Fertil Steril. 2014;102(3):720-727.

12. Kim ED, McCullough A, Kaminetsky J. Oral enclomiphene citrate raises testosterone and preserves sperm counts in obese hypogonadal men, unlike topical testosterone: Restoration instead of replacement. BJU Int. 2016;117(4):677-685.

13. Dumasia K, Kumar A, Kadam L, Balasinor NH. Effect of estrogen receptorsubtype-specific ligands on fertility in adult male rats. J Endocrinol. 2015 225(3):169-180.

14. Akiyama $\mathrm{H}$. [A study on testicular aromatase activity-Spermatogenic damage in high testicular E2 models of rat]. Nihon Hinyokika Gakkai Zasshi. 1997;88(7):649-657.

15. Pavlovich $C P$, King $P$, Goldstein $M$, Schlegel PN. Evidence of a treatable endocrinopathy in infertile men. J Urol. 2001;165(3):837-841.

16. Shoshany O, Abhyankar N, Mufarreh N, Daniel G, Niederberger C. Outcomes of anastrozole in oligozoospermic hypoandrogenic subfertile men. Fertil Steril. 2017;107(3):589-594.

17. Shabsigh A, Kang $Y$, Shabsign $R$, et al. Clomiphene citrate effects on testosterone/estrogen ratio in male hypogonadism. J Sex Med. 2005;2(5): 716-721.

18. Keihani S, Alder NJ, Cheng PJ, Stoddard GJ, Pastuszak AW, Hotaling JM. Obesity and baseline estradiol levels are independent predictors for initiation of anastrozole in hypogonadal men on clomiphene citrate. World J Mens Health. 2020;38:1-9.

19. Ronnberg $L$. The effect of clomiphene citrate on different sperm parameters and serum hormone levels in preselected infertile men: A controlled double-blind cross-over study. Int J Androl. 1980;3(5):479-486.

20. World Health Organization. A double-blind trial of clomiphene citrate for the treatment of idiopathic male infertility. Int J Androl. 1992;15(4): 299-307.

21. Wang C, Chan CW, Wong KK, Yeung KK. Comparison of the effectiveness of placebo, clomiphene citrate, mesterolone, pentoxifylline, and testosterone rebound therapy for the treatment of idiopathic oligospermia. Fertil Steril. 1983;40(3):358-365.

22. Micic S, Dotlic R. Evaluation of sperm parameters in clinical trial with clomiphene citrate of oligospermic men. J Urol. 1985;133(2): 221-222.

23. Surbone A, Vaucher L, Primi MP, et al. Clomiphene citrate effect on testosterone level and semen parameters in 18 infertile men with low testosterone level and normal/low gonadotropines level. Eur J Obstet Gynecol Reprod Biol. 2019;238:104-109.

24. Hussein A, Ozgok Y, Ross L, Rao P, Niederberger C. Optimization of spermatogenesis-regulating hormones in patients with non-obstructive azoospermia and its impact on sperm retrieval: A multicentre study. BJU Int. 2013;111(3 Pt. B):E110-E114.

25. Sokol RZ, Steiner BS, Bustillo M, Petersen G, Swerdloff RS. A controlled comparison of the efficacy of clomiphene citrate in male infertility. Fertil Steril. 1988;49(5):865-870.

26. Helo S, Ellen J, Mechlin C, et al. A randomized prospective double-blind comparison trial of clomiphene citrate and anastrozole in raising testosterone in hypogonadal infertile men. J Sex Med. 2015;12(8): 1761-1769.
27. Patel DP, Brant WO, Myers JB, et al. The safety and efficacy of clomiphene citrate in hypoandrogenic and subfertile men. Int J Impot Res. 2015;27(6): 221-224.

28. Pelusi $C$, Fanelli $F$, Baccini $M$, et al. Effect of clomiphene citrate treatment on the Sertoli cells of dysmetabolic obese men with low testosterone levels. Clin Endocrinol (Oxf). 2020;92(1):38-45.

29. Agarwal A, Virk G, Ong C, du Plessis SS. Effect of oxidative stress on male reproduction. World J Mens Health. 2014;32(1):1-17.

30. ElSheikh MG, Hosny MB, Elshenoufy A, Elghamrawi H, Fayad A, Abdelrahman $S$. Combination of vitamin $E$ and clomiphene citrate in treating patients with idiopathic oligoasthenozoospermia: A prospective, randomized trial. Andrology. 2015;3(5):864-867.

31. Ghanem H, Shaeer O, El-Segini A. Combination clomiphene citrate and antioxidant therapy for idiopathic male infertility: A randomized controlled trial. Fertil Steril. 2010;93(7):2232-2235.

32. Abel BJ, Carswell G, Elton $\mathrm{R}$, et al. Randomised trial of clomiphene citrate treatment and vitamin C for male infertility. Br J Urol. 1982;54(6):780-784.

33. Moradi M, Moradi A, Alemi M, et al. Safety and efficacy of clomiphene citrate and L-carnitine in idiopathic male infertility: A comparative study. Urol J. 2010;7(3):188-193.

34. Guay AT, Bansal S, Heatley GJ. Effect of raising endogenous testosterone levels in impotent men with secondary hypogonadism: Double blind placebo-controlled trial with clomiphene citrate. J Clin Endocrinol Metab. 1995;80(12):3546-3552.

35. Guay AT, Jacobson J, Perez JB, Hodge MB, Velasquez E. Clomiphene increases free testosterone levels in men with both secondary hypogonadism and erectile dysfunction: Who does and does not benefit? Int J Impot Res. 2003;15(3):156-165.

36. Chandrapal JC, Nielson S, Patel DP, et al. Characterising the safety of clomiphene citrate in male patients through prostate-specific antigen, haematocrit, and testosterone levels. BJU Int. 2016;118(6):994-1000.

37. Moskovic DJ, Katz DJ, Akhavan A, Park K, Mulhall JP. Clomiphene citrate is safe and effective for long-term management of hypogonadism. BJU Int. 2012;110(10):1524-1528.

38. Morley JE, Charlton E, Patrick $P$, et al. Validation of a screening questionnaire for androgen deficiency in aging males. Metabolism. 2000;49(9): 1239-1242.

39. Morley JE, Perry HM, 3rd, Kevorkian RT, Patrick P. Comparison of screening questionnaires for the diagnosis of hypogonadism. Maturitas. 2006; 53(4):424-429.

40. Martinez-Jabaloyas JM, Queipo-Zaragoza A, Rodriguez-Navarro R, Queipo-Zaragoza JA, Gil-Salom M, Chuan-Nuez P. Relationship between the Saint Louis University ADAM questionnaire and sexual hormonal levels in a male outpatient population over 50 years of age. Eur Urol. 2007;52(6):1760-1767.

41. Taylor F, Levine L. Clomiphene citrate and testosterone gel replacement therapy for male hypogonadism: Efficacy and treatment cost. J Sex Med. 2010;7(1 Pt 1):269-276.

42. Katz DJ, Nabulsi O, Tal R, Mulhall JP. Outcomes of clomiphene citrate treatment in young hypogonadal men. BJU Int. 2012;110(4): 573-578.

43. Soares $\mathrm{AH}$, Horie NC, Chiang LAP, et al. Effects of clomiphene citrate on male obesity-associated hypogonadism: A randomized, double-blind, placebo-controlled study. Int J Obes (Lond). 2018;42(5):953-963.

44. Mohamed O, Freundlich RE, Dakik HK, et al. The quantitative ADAM questionnaire: A new tool in quantifying the severity of hypogonadism. Int J Impot Res. 2010;22(1):20-24.

45. Dadhich P, Ramasamy R, Scovell J, Wilken N, Lipshultz L. Testosterone versus clomiphene citrate in managing symptoms of hypogonadism in men. Indian J Urol. 2017;33(3):236-240.

46. Habous $\mathrm{M}$, Giona $\mathrm{S}$, Tealab A, et al. Clomiphene citrate and human chorionic gonadotropin are both effective in restoring testosterone in hypogonadism: A short-course randomized study. BJU Int. 2018;122(5): 889-897.

47. Ramasamy R, Scovell JM, Kovac JR, Lipshultz LI. Testosterone supplementation versus clomiphene citrate for hypogonadism: An age matched comparison of satisfaction and efficacy. J Urol. 2014;192(3): 875-879.

48. Emmelot-Vonk MH, Verhaar HJ, Nakhai-Pour HR, Grobbee DE, van der Schouw YT. Low testosterone concentrations and the symptoms of 
testosterone deficiency according to the androgen deficiency in ageing males (ADAM) and Ageing Males' Symptoms rating scale (AMS) questionnaires. Clin Endocrinol (Oxf). 2011;74(4):488-494.

49. Da Ros CT, Averbeck MA. Twenty-five milligrams of clomiphene citrate presents positive effect on treatment of male testosterone deficiency-A prospective study. Int Braz J Urol. 2012;38(4):512-518.

50. Wheeler KM, Smith RP, Kumar RA, Setia S, Costabile RA, Kavoussi PK. A comparison of secondary polycythemia in hypogonadal men treated with clomiphene citrate versus testosterone replacement: A multiinstitutional study. J Urol. 2017;197(4):1127-1131.

51. Francisco R, Jaroudi S, Murtaza Ali M, Frost J, Chemitiganti R, Peiris AN. Clomiphene for hypogonadism complicated by polycythemia. Proc (Bayl Univ Med Cent). 2019;32(1):75-77.

52. Kavoussi PK, Machen GL, Wenzel JL, et al. Medical treatments for hypogonadism do not significantly increase the risk of deep vein thrombosis over general population risk. Urology. 2019;124:127-130.

Cite this article as: Herzog BJ, Nguyen HMT, Soubra A, Hellstrom WJG (2020) Clomiphene citrate for male hypogonadism and infertility: an updated review. Androgens: Clinical Research and Therapeutics 1.1, 62-69, DOI: 10.1089/andro.2020.0005.

$\begin{aligned} & \text { Abbreviations Used } \\ & \mathrm{ADAM}=\text { androgen deficiency in aging males } \\ & \mathrm{AUA}=\text { American Urological Association } \\ & \mathrm{AZ}=\text { anastrozole } \\ & \mathrm{BMI}=\text { body mass index } \\ & \mathrm{CC}=\text { clomiphene citrate } \\ & \mathrm{DVT}=\text { deep vein thrombosis } \\ & \mathrm{FDA}=\text { Food and Drug Administration } \\ & \mathrm{FSH}=\text { follicle-stimulating hormone } \\ & \mathrm{GnRH}=\text { gonadotropin-releasing hormone } \\ & \mathrm{hCG}=\text { human chorionic gonadotropin } \\ & \mathrm{HPG}=\text { hypothalamic-pituitary-gonadal } \\ & \mathrm{IIEF}=\text { International Index of Erectile Function } \\ & \mathrm{IU}=\text { international units } \\ & \mathrm{LH}=\text { luteinizing hormone } \\ & \mathrm{micro-TESE}=\text { microscopic testicular sperm extraction } \\ & \mathrm{qADAM}=\text { quantitative ADAM } \\ & \mathrm{RCT}=\text { randomized controlled trial } \\ & \mathrm{SHIM}=\text { sexual health inventory for men } \\ & \mathrm{T:E}=\text { testosterone-to-estrogen } \\ & \mathrm{TRT}=\text { testosterone replacement therapy }\end{aligned}$

Publish in Androgens: Clinical Research and Therapeutics

Clinical Research and Therapeutics

liebertpub.com/andro 